\title{
A STUDY ON POTENTIAL DRUG - DRUG INTERACTIONS IN MEDICINE DEPARTMENT OF A MULTISPECIALITY TEACHING HOSPITAL
}

\author{
Javedh Shareef ${ }^{1}$, Shannon Lianna Menezes ${ }^{1}$, Tanmay Bhat ${ }^{2}$ \\ ${ }^{1}$ Nitte University, NGSM Institute of Pharmaceutical Sciences, Paneer, Deralakatte, Mangalore, Karnataka 575018, India \\ ${ }^{2}$ Department of General Medicine, Nitte University, KS Hegde Medical Academy and Hospital, P.O. Nityanandanagar, Deralakatte, \\ Mangalore, Karnataka 575018, India
}

\section{ABSTRACT}

Aim of study: Drug-drug interaction (DDI) occurs when two or more drugs are simultaneously administered, where the effect of one drug is altered by the concomitant use of another drug. The prospective observational study aimed to assess the potential drug-drug interactions (pDDIs) in general medicine department of a multispecialty teaching hospital.

Material \& Methods: Data of all the patients admitted in the general medicine department was collected and analyzed for drug-drug interactions by using drug information resources such as "Thomson Reuters MICROMEDEX ${ }^{\circledR} 2.0$ DRUGDEX and drugs.com.

Results: A total of 150 case records were reviewed, 116 (77.33\%) cases were identified with 273 potential drug- drug interactions during the study period. It was observed that out of the 273 DDIs identified, majority $68.13 \%$ of the interactions were moderate in severity followed by $19.78 \%$ were minor and $12.08 \%$ were major. The categorization of onset of drug -drug interactions revealed that $53.47 \%$ were categorized as 'not specified' and the documentation status of drug - drug interactions showed that $56.77 \%$ were 'fair' in nature.

Conclusion: The study highlights the need of regular monitoring of drug therapy in identifying and preventing the medications that have the potential to cause drug-drug interactions thereby minimizing the undesirable outcomes in drug therapy and improving the quality of care.

Keywords: Drug-drug interactions, Poly-pharmacy, severity, hospitalized patients.

Article Info: Received 02 Oct, 2017; Review Completed 09 Nov, 2017; Accepted 11 Nov, 2017; Available online 15 Nov, 2017

\section{Cite this article as:}

Shareef J, Menezes SL, Bhat T, A study on potential drug - drug interactions in medicine department of a multispeciality teaching hospital, Journal of Drug Delivery and Therapeutics. 2017; 7(6):81-87

DOI: http://dx.doi.org/10.22270/iddt.v7i6.1542

*Address for Correspondence

Javedh Shareef, Nitte University, NGSM Institute of Pharmaceutical Sciences, Paneer, Deralakatte,, Mangalore, Karnataka 575018, India. Email: javedh.shareef@gmail.com

\section{INTRODUCTION}

A pharmaceutical drug is a chemical substance when introduced into the body produces an effect which is used to diagnose, cure, treat or prevent a disease or to promote well being. When a patient is suffering from multiple co-morbid conditions, concomitant use of many drugs is often necessary to achieve the goal of therapy. Multiple outcomes are likely to occur when patients use drugs and the possibility of encountering drug-drug interactions could rise in these cases. Drug-drug interactions (DDIs) in patients receiving multi-drug therapy are of wide concern. The term "drug-drug interaction" is used when the effect of one drug is changed or altered by the simultaneous use of another drug. The clinical productivity of such interactions could be antagonism, synergism or idiosyncratism ${ }^{1}$ (Jimmy OD et al., 2012).

There are large numbers of drugs available, due to which, the occurrence of DDI is high from the concomitant use of certain drug pairs. However, from physicians' perspective, some DDIs are not clinically relevant and they believe that there is a requirement of concomitant use of the two drugs in order to achieve suitable therapeutic activity. In cases like these, to prevent the adverse effects that are associated with DDIs, careful monitoring of the laboratory and clinical 
parameters of the patient is looked after. However, prescribing certain drugs together is contraindicated and clinically relevant DDIs could occur in case of concomitant use and may have adverse effects on the patient. Factors that favor the appearance of drug interactions are old age, polypharmacy, genetic factors, wrong choice of drug, wrong dosage, wrong route of administration, errors in taking the drug, failing to take account of hepatic and renal function ${ }^{2}$ (Nag KA et al., 2011).

Potential drug-drug interactions (PDDIs) may include drug contraindications, combinations of drugs that require monitoring and possible dosage adjustments when given concomitantly or drugs which may be beneficial when administered collectively. Consequence of drug interactions occur due to drug related problems which have a negative impact on morbidity, mortality, length of hospitalization, health care cost and quality of life. DDIs can result in anything, from minor morbidities up to fatal consequences. The main causes of hospital admission and mortalities are related to drug interactions and their corresponding adverse effects ${ }^{3}$ (Kaliamurthy $\mathrm{K}$ et al., 2015). The risk of PDDIs increases by the increase in the number of drugs and in patients who are on long term therapy with multiple drugs and co-morbidities. Apt number of drugs for an individual varies greatly, depending on patient's condition, functional status, life expectancy and preferences $^{4}$ (Guthrie B et al., 2015).

Drug interactions may occur by two or additional mechanisms acting together. The mechanisms of interaction can be distributed as pharmacokinetic and pharmacodynamic interactions. "Pharmacokinetic interactions" are those which can affect the processes by which drugs are absorbed, distributed, metabolized and excreted. "Pharmacodynamic interactions" are those in which the effects of one drug are transformed by the presence of another drug at its site of action ${ }^{5}$ (Pasqualetti G et al., 2015).

In developed countries, patient safety has been improved by applying DDI software and by employing clinical pharmacists to detect and prevent DDIs. Physicians in developing countries still identify DDIs based on their own experiences ${ }^{6}$ (Baniasadi $\mathrm{S}$ et al., 2015). Healthcare professionals evaluate the pharmacist's response to drug interactions and recognize their knowledge of pharmacology and appreciate it. Hence, this study acts as an audit to assess the DDIs in the inpatients admitted in the general medicine department of a tertiary care teaching hospital and aims in reducing further occurrence of the same.

\section{MATERIALS AND METHODS}

\section{Study design, site and duration}

A prospective observational study conducted for a period of eight months from November 2016 to June 2017 in hospitalized patient under the general medicine department of a tertiary care teaching hospital centrally located in Dakshina Kannada, Mangaluru. The study was approved by Institutional Human Ethical Committee.

\section{Study criteria \\ Inclusion criteria}

Patients of either gender, aged 18 years and above hospitalized in the general medicine wards, prescribed with two or more drugs.

\section{Exclusion criteria}

The patients receiving less than 24 hours in-patient care and patients who themselves have enrolled in any other investigational studies were excluded from the study.

\section{Data sources}

Patient case sheets including treatment charts and relevant laboratory investigations.

Information received from patient caregivers.

\section{Materials used}

- Patient data collection form.

- Micromedex- drug interaction checking software.

- Stockley's Drug Interactions Book.

- Medscape multidrug interaction checker.

- www.drugs.com

\section{Study procedure}

All the hospitalized patients under the general medicine department were reviewed on daily basis from the day of admission till the day of discharge and those who met the study criteria were enrolled into the study. All the relevant and necessary details of the patients including the demographic data, laboratory parameters and drug therapy details were collected from the patient case notes and by interviewing patient bystanders and healthcare professionals if necessary. The demographic details consists of age, gender, reason for admission, past medical history, medication history, co-morbities and any history of allergic reactions. The recording of laboratory parameters includes haematology, biochemistry and any other tests that were carried out during their hospital stay. The drug therapy details such as dose, duration, frequency, route, time of administration and concomitant drug were also noted. All the collected data were documented in the suitably designed data collection form designed as per the need of the study. The patient drug therapy were reviewed every day and assessed for any drug- drug interactions by using standard text books such as stockley's drug interactions and online resources such as drug.com and micromedex software. The identified potential drugdrug interactions were notified to the healthcare professionals for their appropriate action and were documented by the pharmacist in the drug -drug interaction documentation form. At the end of the study, the evaluation of potential drug-drug interactions was performed among the identified hospitalized patients for its level of severity, onset and documentation status of drug-drug interactions.

\section{Drug-drug interaction documentation form}

A suitable drug-drug interaction documentation form was designed by using various references so as to record the drug-drug interactions. These drug-drug interactions were categorized according to the level of severity 
(mild, moderate and major), time of onset of potential (rapid, delayed and not-specified) and status of documentation (Excellent, Good, Fair, Poor and Unlikely).

\section{Data and statistical analysis:}

The data collected was compiled and entered into the Microsoft excel spread sheet and analyzed by using Statistical package of social sciences (SPSS) for windows (version 16.0). Continuous variable in the text and tables were expressed by mean \pm SD and categorical data were presented as percentage and cumulative frequency.

\section{RESULTS}

General demographic characteristics of study population
A total of 150 patient case records were reviewed in general medicine department during the eight months study period. Out of the 150 case records reviewed, 273 potential drug-drug interactions were identified from 116 patients in which $81(69.82 \%)$ patients were males and $35(30.17 \%)$ patients were females. The mean age of the study population involved was found to be 53.22 \pm 15.04 ranging from 18 to 83 years. Majority of the patients were in the age group of 41-60 years (43.96\%) followed by age group of $61-80$ years $(31.03 \%)$. Among the co-morbidities, cardiovascular diseases (22.60\%) was the most common co-morbidities identified among the study populations followed by endocrine disorders $(17.95 \%)$, infectious diseases $(15.17 \%)$, respiratory conditions (11.14\%) and renal disorders $(8.35 \%)$. Table 2 shows the pattern of co-morbidities among the study populations. The demographic characteristics and the co-morbidities of the of the study subjects is shown in the following Table 1.

Table 1: Demographic details of the study subjects

\begin{tabular}{|c|c|c|}
\hline Gender wise distribution & & \\
\hline Gender & Frequency $(n=116)$ & Percentage \\
\hline Female & 35 & 30.17 \\
\hline Male & 81 & 69.82 \\
\hline Age wise categorization & 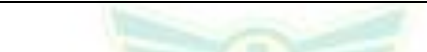 & +4 \\
\hline Age & No of patients $(n=116)$ & Percentage \\
\hline $0-20$ & 5 & 4.31 \\
\hline $21-40$ & 22 & 18.96 \\
\hline $41-60$ & 51 & 43.96 \\
\hline $61-80$ & 36 & 31.03 \\
\hline$\geq 81$ & 2 & 1.72 \\
\hline Co-morbities & & \\
\hline Disease Condition & Frequency & Percentage \\
\hline Endocrine & 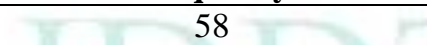 & 17.95 \\
\hline Infectious & 49 & 15.17 \\
\hline Cardiovascular & 73 & 22.60 \\
\hline Respiratory & 36 & 11.14 \\
\hline Renal & 27 & 8.35 \\
\hline Neurological & 13 & 4.02 \\
\hline Immune & 2 & 0.61 \\
\hline Hematological & 16 & 4.95 \\
\hline Bone & 7 & 2.16 \\
\hline Gastrointestinal & 35 & 10.83 \\
\hline Ophthalmology & 4 & 1.23 \\
\hline Dermatological & 3 & 0.92 \\
\hline
\end{tabular}

Table 2: Pattern of medications prescribed in the study populations

\begin{tabular}{|l|l|l|}
\hline Category of drugs & Frequency of drugs & Percentage \\
\hline Cardiovascular agents & 357 & 17.24 \\
\hline Anti-infective agents & 369 & 17.82 \\
\hline Nutritional products & 302 & 14.58 \\
\hline Anti-diabetic agents & 345 & 16.66 \\
\hline Steroids & 48 & 2.31 \\
\hline Central nervous system agents & 185 & 8.93 \\
\hline Respiratory & 201 & 9.71 \\
\hline Gastro intestinal agents & 263 & 12.70 \\
\hline
\end{tabular}


System wise distribution of class of drugs prescribed among the study subjects

The number of drugs prescribed to the patients in the study has been categorized according to the British national formulary system wise classification. As per the classification, most of the patients in our study population received drugs categorized under antiinfective agents $(17.82 \%)$ followed by cardiovascular drugs $(17.24 \%)$ and anti-diabetic agents (16.66\%). Table 2 shows the overall pattern of medications that were prescribed in the study populations.

Number of medications received by each patient of the study population

Considering the number of drugs received by the patients, the average number of drugs received per patient was found to be $13.05 \pm 5.764$. Most of the patients $(34.67 \%)$ in our study received 6 -10 drugs during their hospital stay. The number of medications received by the study population during their hospital stay is shown in the following figure 1.

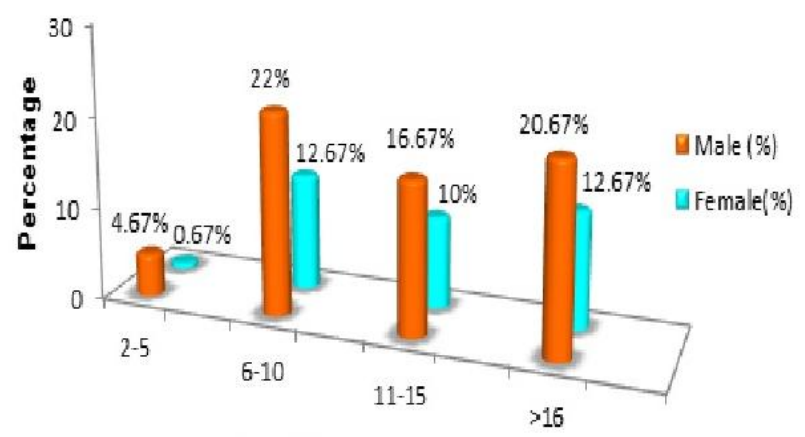

No. of drugs

Figure1. Number of drugs recieved per prescription

Distribution of cases with number of drug-drug interactions

The number of potential DDI ranged from 1 to 10 in which 12 cases $(10.34 \%)$ showed one potential DDI, 11 cases $(9.48 \%)$ showed two potential DDIs and 44 cases $(37.93 \%)$ showed more than ten potential drug- drug interactions. The distribution of cases with number of drug-drug interactions is shown in the following table 3.
Table 3: Distribution of cases with number of drugdrug interactions

\begin{tabular}{|c|c|c|}
\hline $\begin{array}{c}\text { No. of interactions } \\
\text { per patient }\end{array}$ & Frequency & $\begin{array}{c}\text { Percentage } \\
(\mathbf{\%})\end{array}$ \\
\hline $\mathbf{1}$ & 12 & 10.34 \\
\hline $\mathbf{2}$ & 11 & 9.48 \\
\hline $\mathbf{3}$ & 8 & 6.89 \\
\hline $\mathbf{4}$ & 10 & 8.62 \\
\hline $\mathbf{5}$ & 9 & 7.75 \\
\hline $\mathbf{6}$ & 6 & 5.17 \\
\hline $\mathbf{7}$ & 7 & 6.03 \\
\hline $\mathbf{8}$ & 5 & 4.31 \\
\hline $\mathbf{9}$ & 4 & 3.44 \\
\hline$\geq \mathbf{1 0}$ & 44 & 37.93 \\
\hline
\end{tabular}

Commonly involved drugs causing potential drugdrug interactions

Of the total 273 drug - drug interactions, the most common drugs involved in causing drug -drug interactions was found to be pantoprazole [54(19.78\%)] followed by aspirin [36(13.18\%)] and statins [34(12.45\%)]. The involvement of other class of drugs in developing potential drug-drug interactions was shown in the following figure 2 .

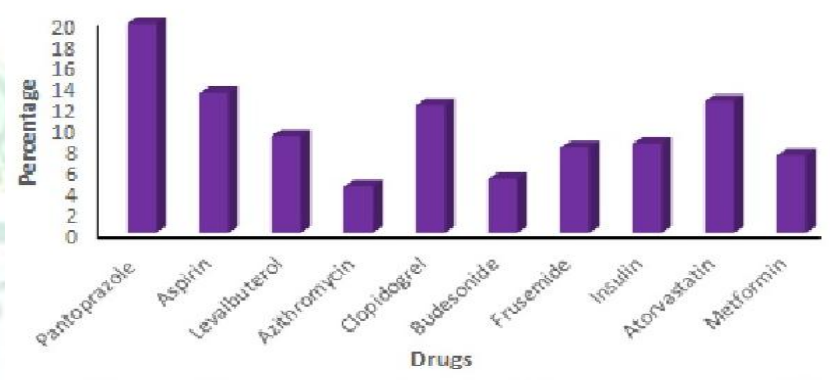

Figure 2.Commonly involved drugs causing pDDIs

Most prevalent potential DDIs among the study population

The most commonly occurring interaction in the study was found to be between atorvastatin and pantoprazole (28) followed by budesonide and levalbuterol (18), aspirin + pantoprazole (17), pantoprazole with torsemide (15) and pantoprazole in combination with propranolol (14). The most prevalent potential drug-drug interactions among the study populations are shown in the table 4 .

Table 4: Most prevalent drug-drug interactions in the study subjects

\begin{tabular}{|c|c|c|c|}
\hline Sl. No. & Drug combination & No. of cases & Severity of DDIs \\
\hline $\mathbf{1}$ & Atorvastatin + Pantoprazole & 28 & Moderate \\
\hline $\mathbf{2}$ & Budesonide + Levalbuterol & 18 & Minor \\
\hline $\mathbf{3}$ & Aspirin + Pantoprazole & 17 & Minor \\
\hline $\mathbf{4}$ & Pantoprazole + Torsemide & 15 & Moderate \\
\hline $\mathbf{5}$ & Pantoprazole + Propranolol & 14 & Moderate \\
\hline $\mathbf{6}$ & Furosemide + Pantoprazole & 12 & Moderate \\
\hline $\mathbf{7}$ & Pantoprazole + Theophylline & 12 & Moderate \\
\hline $\mathbf{8}$ & Iron + Pantoprazole & 11 & Minor \\
\hline $\mathbf{9}$ & Levalbuterol + Terbutaline & 11 & Moderate \\
\hline $\mathbf{1 0}$ & Budesonide + Terbutaline & 11 & Moderate \\
\hline $\mathbf{1 1}$ & Clopidogrel + Pantoprazole & 10 & Moderate \\
\hline $\mathbf{1 2}$ & Azithromycin + Levalbuterol & 10 & 10 \\
\hline $\mathbf{1 3}$ & Pantoprazole + Rifaximin & &
\end{tabular}


Categorization of drug-drug interactions according to the level of severity, based on their onset and according to their documentation status.

According to severity level classification of drug-drug interactions, $68.13 \%$ were moderate in severity, $19.78 \%$ were minor interactions and $12.08 \%$ were major interactions found. Based upon the onset of drug-drug interactions, it was found that majority of the interactions' (53.47\%) onset was not specified and the delayed onset of interaction was found to be $30.03 \%$ and rapid onset were seen in $16.48 \%$ of interactions. Of the total 273 potential drug-drug interactions identified in the study, $8.42 \%$ were documented as excellent followed by $34.79 \%$ were good and $56.77 \%$ were fair in nature. The study could not identify any drug-drug interactions that have been documented under the category poorly and unlikely. The classification of drugdrug interactions according to their level of severity, based on their onset and according to their documentation status is shown in the following Table 5.

Table 5: types of drug-drug interactions

\begin{tabular}{|c|c|c|}
\hline Types of drug interactions & $\begin{array}{c}\text { Total number of drug } \\
\text { interactions (n=273) }\end{array}$ & Percentage \\
\hline Classification based on severity & 33 & 12.08 \\
\hline Major & 186 & 68.13 \\
\hline Moderate & 54 & 19.78 \\
\hline Minor & 82 & 30.03 \\
\hline Classification based on Onset & 45 & 16.48 \\
\hline Delayed & 146 & 53.47 \\
\hline Rapid & 155 & 56.77 \\
\hline Classification based on their documentation status & 34.79 \\
\hline Fair & 95 & 8.42 \\
\hline Good & 23 & \\
\hline Excellent & \multicolumn{2}{|c|}{} \\
\hline
\end{tabular}

\section{DISCUSSION}

Drug-drug interactions (DDIs) are a concern for all stake holders, especially patients and this risk increases as greater number of medications was commonly used to manage complex conditions. The present study revealed that the overall prevalence of potential drug-drug interactions were $77.33 \%$ which comparable to the other studies which encountered potential drug-drug interactions ranging from $45 \%-78 \%^{7,8,9}$ ( Ismail $\mathrm{M}$ et al 2011; Cruciol-Souza JM et al 2006; Lubinga SJ et al 2011). A male predominance in patients with drug related problems were seen when compared to female populations. It indicates that male patients might have received more co-prescription of multiple medications for several physical and chronic health conditions. At present the available results in the literature regarding the role of gender are incongruous and the increase in frequency of drug -drug interactions in males ${ }^{10,11}$ (Umretiya T. et.al., 2015; Bhagavathula A.S. et al., 2014) are not found by all researchers ${ }^{12,13}$ (Patel P.S. et al., 2014; Teixeira J.J.V et al., 2012).

The mean age in the present study was $53.22 \pm 15.04$. Majority (44\%) of the patients in this study belonged to age group 41-60 years and also, the potential drug-drug interactions were widely seen in patients of the same age group. A study showed similar results ${ }^{14}$ (Ahmad A et al., 2015) but is in contrast with another study in which majority was seen in lower age group ${ }^{15}$ (Vonbach $\mathrm{P}$ et al., 2008). The reason behind this may probably be because their study was a cross sectional study conducted in an underdeveloped country. But the present study was conducted in hospitalized patients in the general medicine ward in south India where elderly individuals were exposed to more multiple regimens than younger individuals, which increase the risk of pDDIs.

The average medications prescribed per patient, in the study population was $13.05 \pm 5.764$. the incidence of potential drug-drug interactions is close to $40 \%$ in patients taking 5 drugs and exceeds $80 \%$ in patients taking more than seven medications. This result was contrary to a study carried out in outpatient general medicine department of a tertiary care teaching hospital $^{16}$ (Baxter K et. al., 2014). This discrepancy could have occurred because of the different designs of the studies. Our study carried out in hospitalized patients where the likelihood of causing potential drug-drug interactions are very high because of sever and multiple illness, co-morbid conditions, chronic therapeutic regimen, multiple medications and frequent changes in drug therapy.

Cardiovascular disorders were the most common clinical condition observed in this study. This is because; the patients involved in the study had more cardiovascular co-morbidities either on admission, or as past medical history. Also, the recent studies show that India faces a burden of cardiovascular diseases as the highest occurring disease. The study results showed the same clinical condition in majority of the admitted patients in some of the studies ${ }^{17,}{ }^{18}$ (Soherwardi S et al., 2015) (Dominic A et.al., 2015).

While categorizing the number of drugs received by the study subjects, it was observed that anti-infective agents were the most commonly prescribed ones in general 
medicine department, followed by cardiovascular agents. Since, in the study, cardiovascular disease followed by endocrine, infectious and respiratory is more observed, more number of antimicrobials agents are prescribed and given as treatment and prophylaxis for these diseases. Hence, more number of anti-infective agents are prescribed overall. Cardiovascular diseases being majority in occurrence, makes it a possible reason for cardiovascular agents to be prescribed ${ }^{19}$ (Kumaraswamy RC et al., 2014).

More than 10 interactions were seen in majority (38\%) of the study population conducted in this study whereas majority of patients had one interaction in a previous study $^{20}$ (Sharma S. et al., 2014). This discrepancy could have occurred because of the difference in selection of the patients. Sharma and co-workers carried out the study in patients with cardiovascular diseases where as our study included all the patients irrespective of their diagnosis.

The most frequently occurring interaction identified in our study was between atorvastatin and pantoprazole. As majority of the patients were suffering from cardiovascular disease, statins were prescribed for the treatment of arthrosclerosis and also as prophylaxis for the secondary prevention of cardiovascular diseases. When the patients were prescribed with multiple medications, there is a possibility that it might lead to occurrence of drug induced gastritis leading to coprescribing of proton pump inhibitors. Also studies carried out by various authors in different setting showed that Ceftriaxone + Furosemide and Acetaminophen + Pantoprazole were the most common pairs of drug-drug interactions identified in their study $^{21,22}$ (Sweileh WM et al., 2014) (Guo J J et al., 2015). This difference between the present study and other studies may possibly be due to diverse factors including high utilization of medications which have more potential for interaction, different study designs and difference in software used.

The most noticeable drug involved in causing pDDIs in this study is pantoprazole But few other studies that have carried out previously has shown that ciprofloxacin and ACE inhibitors are responsible for more number of drug-drug inetractions ${ }^{23,24}$ (Nabovati E et al., 2016) (Nikolic B et al., 2014). The results of this study also highlight this area as most of the DDIs were identified in such prescriptions. Awareness program must be raised by stakeholders to educate health professionals regarding the rational use of drugs in these conditions.

According to severity, this study showed majority $(68.13 \%)$ of interactions as moderate followed by minor and then major in severity. These results are in line with the other studies which also showed that majority of the drug-drug interactions were 'moderate' in level of severity $^{25}$ (Van Leeuwen RWF et al., 2013). Interactions being moderate in severity explain a condition wherein, exacerbation of the patient's condition is seen. Such conditions may require an alteration in therapy.

According to onset of pDDIs, majority (53.47\%) of interactions in our study belongs to the category 'not specified'. These findings were comparable with the results obtained that have reported previously ${ }^{26}$ (Doan J et. al., 2013). This indicates that the interactions will not be evident immediately on administration of drugs, but when these drugs are continued, it would result in adverse effects. In cases like these, patients have to be closely and carefully monitored by the physician and the nursing staff.

The documentation of 155 identified drug -drug interactions were fair $(56.77 \%), 95(34.79 \%)$ were good and $23(8.82 \%)$ were excellent in nature. Similar results were seen in a study conducted previously ${ }^{27}$ (TavakoliArdakani M et al., 2013). Fair documentation status reveals a state where poor documentation is available but pharmacological considerations may perhaps lead clinicians to suspect the existence of a drug interaction.

\section{CONCLUSION}

The present study shows a high prevalence of potential drug-drug interactions in hospitalized patients of general medicine wards of tertiary care hospital. The use of electronic database systems as decision support tools, automated prescription alerts to doctors, conducting educational programs and vigilant towards drug selection can decrease the negative outcomes of pDDIs. So a regular review of the drug therapy by a clinical pharmacist in a multidisciplinary team may helps to identify and prevent potential drug-drug interactions especially in patients with chronic disease receiving multiple associated with their co-morbid conditions. These will in turn help to optimize drug therapy, improve the quality of care and condense the undesirable outcomes in the patient drug therapy.

\section{Acknowledgment}

We would like to express our gratitude to the Medical Superintendent of Justice K S Hegde Charitable Hospital, Deralakatte, Mangalore for his support and cooperation in carrying out the study. Heartfelt thanks to Head of the general medicine department for giving permission to conduct the study.We are also very thankful to the Principal, NGSM Institute of Pharmaceutical sciences for providing necessary support and encouragement to the study.

Conflict of Interest: None declared 


\section{REFERENCES}

1. Jimmy OD, Shobha Rani RH, Indra R, Ramjan S. Study of Drug-drug Interactions in the Medication Charts in Medicine Wards at a Tertiary Care Hospital, Bangalore. Ind J of Pharm. Pract., 2012; 5(4):61-4.

2. Nag KA, Umesh M, Churi S. Assessment of Drug-Drug Interactions in Hospitalized Patients in India. Asian J Pharm Clin Res., 2011; 4(1):62-65.

3. Kaliamurthy K, Kumar A, Punniyakotti S, Devanandan P. Study of Drug-Drug Interactions in General Medicine Department of a Tertiary Care Hospital. J App Pharm Sci. 2015; 5(12):122-124.

4. Guthrie B, Makubate B, Hernandez-Santiago V, Creischulte The Rising Tide of Polypharmacy and Drug-drug Interactions: Population Database Analysis 1995-2010. BMC Medicine, 2015; 74(13):1-10.

5. Pasqualetti G, Tognini S, Calsolaro V, Polini A, Monzani F. Potential Drug-Drug Interactions in Alzheimer Patients with Behavioral Symptoms. Clin Interv Aging, 2015; 10:14571464.

6. Baniasadi S, Farzanegan B, Alehashem M. Important Drug Classes Associated with Potential Drug-drug Interactions in Critically Ill Patients: Highlights for Cardiothoracic Intensivists. Ann. Intensive Care, 2015; 44(5):1-8.

7. Ismail $\mathrm{M}$, Iqbal $\mathrm{Z}$, Khattak MB, Javaid A, Khan TM. Prevalence, type and predictors of potential drug-drug interactions in pulmonary ward of a teriary care teaching hospital. Afr J Pharm Pharmacol, 2011; 5(10):1303-1309.

8. Cruciol-Souza JM, Thomson JC. Prevalence of potential drugdrug interactions and its associated factors in a Brazilian teaching hospital. J Pharma Pharmaceut Sci, 2006; 9(3):427433.

9. Lubinga SJ, Uwiduhaye E, Potential drug-drug interactions on in-patient medication prescriptions at Mbarara Regional Referral Hospital (MRRH) in western Uganda: Prevalence, clinical importance and associated factors. Afr Health Sci, 2011; 11(3):499-503.

10. Umretiya T, Patil NR, Manjunath G, Kumar C. Assessment of Potential Drug-Drug Interactions in the Department of Medicine at Basaweshwara Teaching and General Hospital Gulbarga. RGUHS J Pharm Sci., 2015; 5(3):90-96.

11. Bhagavathula AS, Berhanie A, Tigistu $H$, Abraham $Y$, Getachew Y, Khan TM. Prevalence of Potential Drug-Drug Interactions among Internal Medicine Ward in University of Gondar Teaching Hospital, Ethiopia. Asian Pac J Trop Biomed., 2014; 4(1):S204-S208.

12. Patel PS, Rana DA, Suthar JV, Malhotra SD, Patel VJ. A Study of Potential Adverse Drug-Drug Interactions among Prescribed Drugs in Medicine Outpatient Department of a Tertiary Care Teaching Hospital. J Basic Clin Pharma., 2014; 5:44-48.

13. Teixeira JJV, Crozatti MTL, dos Santos CA, Romano-Lieber NS. Potential Drug-Drug Interactions in Prescriptions to Patients over 45 Years of Age in Primary Care, Southern Brazil. PLoS One., 2012; 7(10):1-6.
14. Ahmad A, Khan MU, Haque I, Ivan R, Dasari R, Revanker M Et al. Evaluation of Potential Drug-Drug Interactions in General Medicine Ward of Teaching Hospital in Southern India. J Clin Diagn Res, 2015; 9(2):10-13.

15. Vonbach P, Dubied A, Krahenbuhl S, Beer JH. Prevalence of Drug-Drug Interactions at Hospital Entry and During Hospital Stay of Patients in Internal Medicine. Eur J Intern Med, 2008; 19:413-420.

16. Baxter K, Stockley I. Stockley's Drug Interactions. Ninth Edition. London: Pharmaceutical Press; 2010.P. 15-24.

17. Soher Wardi S, Chogtu B, Faizal P. Surveillance of the Potential Drug-Drug Interactions in the Medicine Department of a Tertiary Care Hospital. J Clin Diagn Res, 2012; 6(7):1258-1261.

18. Dominic A, Joseph J, Augustine RM, Begum R, Nanjwade BK. Study of Drug Use Evaluation on Oral Antihyperglycemic Agents in Type 2 Diabetes Mellitus and Their Potential Drug-Drug Interactions. WJPPS, 2016; 5(7):1884-1896.

19. Kumaraswamy RC, Ramani JU, Ramesh B, Radadiya M, Soumya B, Patel D. Prevalence of Polypharmacy and Drug to Drug Interactions in a Tertiary Care Teaching Hospital. Int. Res. J. Pharm, 2014; 5(10):778-782.

20. Sharma S, Chhetri HP, Alam K. A Study of Potential Drug-Drug Interactions among Hospitalized Cardiac Patients in a Teaching Hospital in Western Nepal. Indian J. Pharmacol, 2014; 46(2):152-156.

21. Sweileh WM, Sawalha AF, Jaradat NA. Extent of Potential Drug Interactions among Patients Receiving Anti-hypertensive Medications. Saudi Med J, 2005; 26:548-552.

22. Guo JJ, Wu J, Kelton CML, Jing Y, Fan H, Keck PE Et.al. Exposure to Potentially Dangerous Drug-Drug Interactions Involving Antipsychotics. Psychiatr Serv, 2012; 63(11):10801088

23. Nabovati E, Vakili-Arki H, Taherzadeh Z, Saberi MR, AbuHanna A, Eslami S. Incidence Rate and Pattern of Clinically Relevant Potential Drug-Drug Interactions in a Large Outpatient Population of a Developing Country. Res Pharm Sci, 2016; 11(3):233-242.

24. Nikolic B, Jankovic S, Stojanov O, Popovic J. Prevalence and Predictors of Potential Drug-Drug Interactions. Cent Eur J Med, 2014; 9(2):348-356.

25. Van Leeuwen RWF, Brundel DHS, Neef C, Van Gelder T, Mathijssen RHJ, Burger DM Et.al. Prevalence of Potential Drug-Drug Interactions in Cancer Patients Treated with Oral Anticancer Drugs. Br. J. Cancer, 2013; 108:1071-1078.

26. Doan J, Zakrzewski-Jakubiak H, Roy J, Turgeon J, Tannenbaum C. Prevalence and Risk of Potential Cytochrome P450-Mediated Drug-Drug Interactions in Older Hospitalized Patients with Polypharmacy. Ann. Pharmacother, 2013; 47:324-332.

27. Tavakoli-Ardakani M, Kazemian K, Salamzadeh J, Mehdizadeh M. Potential of Drug Interactions among Hospitalized Cancer Patients in a Developing Country. Iran J Pharm Res, 2013; 12:175-182. 